\title{
CARACTERIZAÇÃO DAS TRANSFORMAÇÕES DE FASES ISOTÉRMICAS E DOS SEUS RESPECTIVOS PRODUTOS EM TRES AÇOS EUTETÓIDES DE APLICAÇÃO FERROVIÁRIA
}

\author{
Karine Fernandes Rodrigues ' \\ Gabriel Marques Magalhães Mourão' \\ Geraldo Lúcio de Faria'
}

\section{Resumo}

Artigos recentemente publicados vêm destacando a importância do conhecimento sobre a cinética de transformação de fases em aços eutetóides aplicados em ferrovias, visando o aprimoramento de processos de fabricação e de soldagem. Nesse sentido, o presente trabalho apresenta um estudo de caracterização da cinética de decomposição isotérmica da austenita em três aços atualmente utilizados no mundo para a fabricação de trilhos ferroviários, sendo dois de classificação premium e um de classificação standard. Os aços estudados foram caracterizados em seu estado de entrega e, por meio de ensaios de dilatometria, as temperaturas críticas de austenitização e os intervalos de tempo de decomposição da austenita foram medidos. Diagramas tempo-temperatura-transformação (TTT) foram determinados. A influência de alguns parâmetros como o espaçamento interlamelar perlítico original e o tamanho de grão austenítico prévio sobre as transformações de fases e sobre as microestruturas resultantes, foram discutidos. Mostrou-se ainda que, a partir de tratamentos isotérmicos bem planejados, é possível a obtenção de uma microestrutura majoritariamente bainítica em aços eutetoides com composições químicas relativamente simples.

Palavras-chave: Aço eutetóide; Trilhos ferroviários; Transformação de fases; Diagrama TTT.

\section{CHARACTERIZATION OF THE ISOTHERMAL PHASES TRANSFORMATIONS AND THE RESPECTIVES PRODUCTS IN THREE EUTECTOID STEELS FOR RAILROAD APPLICATION}

Recently published papers have been enhancing the importance of understanding about the kinetics of phase transformation in eutectoid steels applied to railways, aiming the improvement of the manufacturing and the welding processes. In this sense, this work presents a characterization study on the austenite's isothermal decomposition kinetics in three steels currently used worldwide in the manufacturing of railway tracks, being two of then premium and the other standard. The steels studied were characterized at initial state and, through dilatometry, the austenitization critical temperatures and the austenite decomposition's time intervals were measured. Time-temperature-transformation (TTT) diagrams were determined. The influence of some parameters such as the original pearlite interlamellar spacing and the prior austenitic grain's size on the phase transformations and the resulting microstructures, was discussed. The study also showed that stemming from well-planned isothermal treatments, it is possible to obtain a mostly-bainitic microstructure in eutectoid steels of fairly simple chemical compositions.

Keywords: Eutectoid steel; Railway tracks; Phase transformation; TTT diagram.

\section{INTRODUÇÃO}

Com a crescente demanda pelo transporte ferroviário, atualmente o principal objetivo das concessionárias é aumentar o seu rendimento anual, elevando o volume de carga transportada por eixo, a velocidade média das composições e o fluxo sobre os trilhos. Dessa forma, as ferrovias têm sido submetidas a condições cada vez mais severas de solicitação mecânica.
Neste contexto, a exigência por trilhos fabricados a partir de aços que apresentem bom desempenho mecânico, assim como a aplicação de técnicas de soldagem aprimoradas que requerem menos manutenção, tem sido cada vez maior [I-3].

Os aços perlíticos são amplamente utilizados na indústria ferroviária por apresentarem elevada resistência

'Universidade Federal de Ouro Preto - UFOP, Ouro Preto, MG, Brasil. E-mail: karinefernandes.bio@hotmail.com 
mecânica e ao desgaste, assim como tenacidade satisfatória. As propriedades mecânicas dos aços perlíticos são controladas pelas microestruturas desenvolvidas em seu processamento termomecânico, especialmente por características como tamanho de grão austenítico prévio, espaçamento interlamelar e tamanho da colônia de perlita [4-10].

Devido à importância do conhecimento a respeito das transformações de fases desses aços durante o processo de fabricação, diversas pesquisas estão sendo desenvolvidas para o entendimento tecnológico de rotas alternativas para produção e manutenção de aços eutetóides de aplicação ferroviária $[2,3,1$ I ] . Além disso, tendo em vista a tendência atual de se utilizar tecnologias de soldagem para a união de trilhos, estudos estão sendo feitos para propor possíveis soluções para minimizar o efeito maléfico das zonas termicamente afetadas em juntas soldadas de trilhos [12,13].

Segundo a norma AREMA [14], os aços para trilhos, que apresentam uma microestrutura majoritariamente perlítica, podem ser classificados em duas classes: standard e premium. Os trilhos perlíticos standard, que não são submetidos a um resfriamento controlado durante seu processamento, apresentam espaçamento interlamelar relativamente grosseiro, fazendo com que estes aços apresentem valores de dureza relativamente baixos, cerca de $300 \mathrm{HB}$. Os trilhos premium, são submetidos a um resfriamento controlado após a etapa de laminação a quente apresentam menor espaçamento interlamelar e, portanto, maior dureza, variando entre 340 e $390 \mathrm{HB}$ [15].

Apesar da microestrutura $100 \%$ perlítica ser a mais utilizada na indústria ferroviária, tem havido um maior foco na melhoria da dureza dos aços para trilhos com o desenvolvimento de microestruturas alternativas. Uma alternativa bem sucedida aos trilhos fabricados a partir de aços perlíticos, são os trilhos fabricados a partir de aços bainíticos. De fato, estes aços podem atingir uma dureza maior do que os aços convencionais perlíticos. Os aços bainíticos possuem uma excelente combinação de resistência ao desgaste e à fadiga. Aglan et al. [16] analisaram e compararam as propriedades mecânicas, o tipo de fratura e a tenacidade à fratura de um aço bainítico para trilhos com as de um aço perlítico premium. Os autores verificaram que o aço bainítico tem propriedades mecânicas e tenacidade à fratura superiores em comparação com o aço perilítico. Por outro lado, Lee e Polycarpou [15] verificaram que o trilho de aço perlítico, com menor dureza inicial, obteve um maior endurecimento que o aço bainítico, inicialmente mais resistente, devido as tensões em serviço acumuladas nos trilhos e, portanto, obteve melhor desempenho em desgaste.

Nesse contexto, este trabalho apresenta um estudo sobre a cinética de transformação de fases isotérmica de três aços de aplicação ferroviária sendo dois da linha premium $(\mathrm{A}$ e $\mathrm{B})$ e um padrão standard $(\mathrm{C})$. Estudos dilatométricos de decomposição da austenita foram realizados em diferentes isotermas, destacando os efeitos da composição química, microestrutura original e tamanho de grão austenítico prévio.

\section{MATERIAIS E MÉTODOS}

\section{I Materiais}

No presente trabalho foram avaliados três diferentes tipos de aços aplicados na fabricação de trilhos ferroviários, identificados como A, B e C. Os resultados da análise química realizada na região do boleto dos três aços analisados são apresentados na Tabela I.

Como já mencionado, a norma AREMA [14] classifica os aços ferroviários como do tipo premium ou standard em função da combinação de três critérios que são: atender os limites superiores e inferiores de especificação química, submissão ou não dos trilhos laminados a quente a tratamentos térmicos de resfriamento acelerado no boleto e dureza final alcançada no boleto. Nesse contexto, e observando-se os critérios acima mencionados de forma coletiva, os fabricantes dos aços em estudo os classificam no mercado internacional como sendo os aços $\mathrm{A}$ e $\mathrm{B}$ da classe premium e o C da classe standard.

Ao se analisar composição química de forma isolada, pode-se observar que os aços A e B apresentam valores, em sua maioria, de acordo com o especificado para a classe de trilhos premium, como esperado. Da mesma forma, a composição química do aço $\mathrm{C}$, apresenta valores, em sua maioria, de acordo com o especificado para a classe de trilhos standard, segundo a norma AREMA [14]. Pode-se observar que o aço $C$ apresenta menor teor de carbono e maior teor de manganês comparado aos aços A e B. O menor teor de manganês apresentado pelos aços premium se deve ao fato de que esses aços são, no processo de manufatura, submetidos ao tratamento térmico no boleto após a laminação a quente, diferente do aço $C$ que não é submetido a nenhum tipo

Tabela I. Composição química dos aços estudados (\% em massa)

\begin{tabular}{ccccccc}
\hline Elemento & $\mathbf{C}$ & $\mathbf{S i}$ & $\mathbf{S}$ & $\mathbf{M n}$ & $\mathbf{P}$ & $\mathbf{C r}$ \\
\hline $\mathbf{A}$ & 0,792 & 0,304 & 0,004 & 0,883 & 0,017 & 0,209 \\
$\mathbf{B}$ & 0,763 & 0,223 & 0,010 & 1,017 & 0,016 & 0,211 \\
$\mathbf{C}$ & 0,731 & 0,539 & 0,005 & $\mathbf{I}, 240$ & $\mathbf{0 , 0 1 5}$ & 0,218 \\
\hline Elemento & $\mathbf{M o}$ & $\mathbf{N i}$ & $\mathbf{A l}$ & $\mathbf{V}$ & $\mathbf{N b}$ & $\mathbf{T i}$ \\
\hline A & 0,016 & 0,023 & 0,005 & 0,002 & 0,002 & 0,000 \\
B & 0,000 & 0,018 & 0,003 & 0,001 & 0,000 & 0,000 \\
C & 0,017 & 0,026 & 0,006 & 0,003 & 0,017 & 0,002 \\
\hline
\end{tabular}


de resfriamento controlado. Dessa forma a diminuição da temperabilidade dos aços premium se faz necessária para evitar a ocorrência de estrutura martensítica, que não é indesejável em aplicações ferroviárias devido à sua baixa tenacidade.

Deve-se ressaltar, ainda, que era esperado que os aços $A$ e $B$ apresentassem maior teor de elementos de liga microligantes comparados ao aço $C$, por se tratarem de aços de classificação premium, uma vez que se admite, em geral, que o retardo da recristalização da austenita devido à fina precipitação de carbonetos durante a laminação à quente é responsável pelo refino de grão observado em aços microligados ao nióbio, vanádio e titânio.

\subsection{Procedimentos Experimentais}

\subsection{Caracterização microestrutural do estado de entrega}

Para a caracterização dos aços no estado de entrega, a amostragem e a confecção dos corpos de prova se deu a partir da seção transversal em relação à direção de laminação do trilho, em uma região a $15 \mathrm{~mm}$ da superfície de rolamento do boleto do trilho, como mostra a Figura I.

Para as análises metalográfica, as amostras dos aços foram cortadas, embutidas, lixadas e polidas segundo os procedimentos usuais recomendados pela norma ASTM E3 [17]. Após o polimento, realizou-se ataque químico com reativo Nital $2 \%$ para revelar a microestrutura e que posteriormente foi analisada no microscópio eletrônico de varredura (MEV). Para tal finalidade, utilizou-se o microscópio eletrônico de varredura modelo TESCAN VEGA3, para cada aço estudado foram determinados os tamanhos das colônias de perlita e o espaçamento interlamelar médio.

O tamanho médio da colônia de perlita foi determinado utilizando uma técnica de ataque térmico em um forno de atmosfera controlada. Cada amostra permaneceu dentro do forno por aproximadamente 15 minutos, em uma atmosfera com baixa pressão parcial de oxigênio com fluxo controlado de argônio (I $4 \mathrm{~L} / \mathrm{min}$.), até atingir uma temperatura de $680^{\circ} \mathrm{C}$ e posteriormente por um tempo entre I 5 a 20 minutos, nesta temperatura, para realização do ataque térmico, evitando a austenitização do material. Posteriormente, elas foram analisadas em microscópio óptico e os tamanhos médios das colônias de perlita foram medidos por meio do método dos interceptos linear (Método de Heyn), de acordo com a norma ASTM EII 2 [18].

As medidas dos espaçamentos interlamelares foram realizadas sobre imagens obtidas no MEV. Observando-se uma amostra plana atacada com reagente em um microscópio eletrônico de varredura, é possível medir o espaçamento interlamelar amostrando-se aquelas regióes de menores espaçamentos e desprezando-se as demais [19-2I]. Dessa forma, com auxílio de uma régua virtual, as medidas dos espaçamentos entre as lamelas de perlita foram realizadas fazendo-se uso da Equação I, onde $\lambda$ é o valor do espaçamento interlamelar; VB é a medida da barra de escala da imagem, em $\mu \mathrm{m} ; \mathrm{MB}$ é a medida equivalente da barra de escala em $\mathrm{mm}(\mathrm{I}: \mathrm{I})$; ML é a medida da linha teste, traçada perpendicularmente às lamelas de perlita, em $\mathrm{mm}(\mathrm{I}: \mathrm{I})$; e NLé o número de lamelas de cementita interceptadas pela linha teste, como mostra a Figura 2. Foram utilizadas 3 linhas em cada imagem, totalizando 30 imagens, para cada aço, com ampliação de 20 mil vezes, para a obtenção de valores médios representativos.

$$
\lambda=\frac{\text { VB.ML }}{\text { MB.NL }}
$$

Os ensaios de microdureza Vickers, no estado de entrega, foram realizados por meio de 10 indentações.

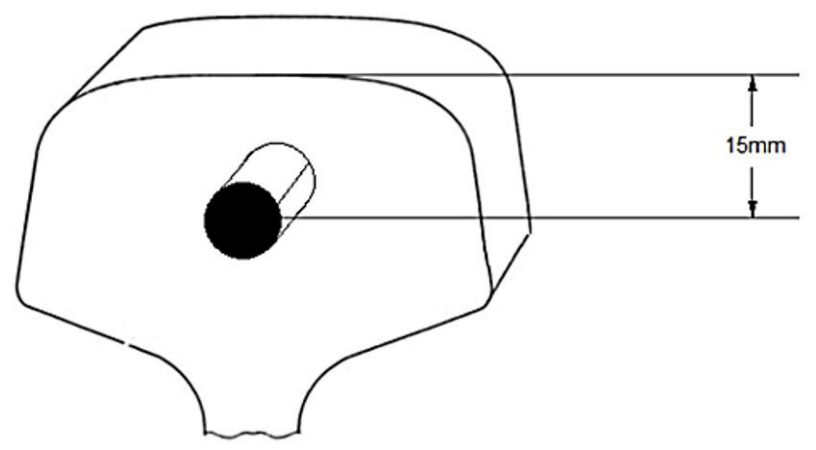

Figura I. Localização de retirada dos corpos de prova para análise microestrutural, a região sombreada representa a superfície analisada.

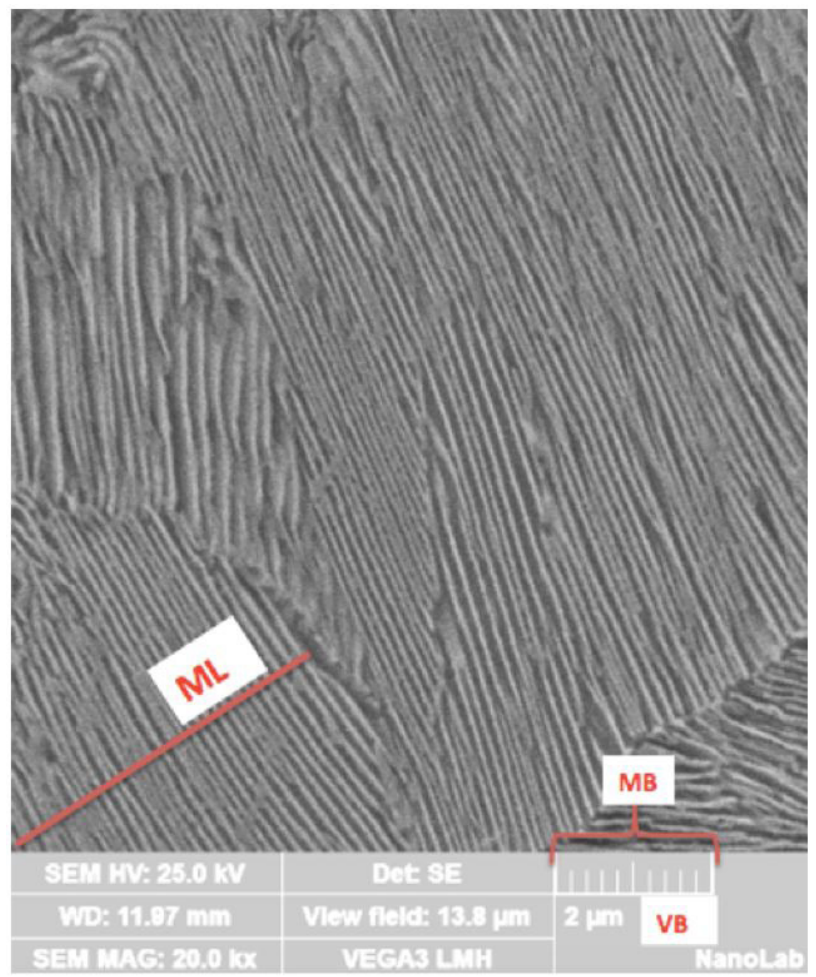

Figura 2. llustração da metodologia de medição do espaçamento interlamelar perlítico a partir da Equação I. 
A carga aplicada foi de $200 \mathrm{gf}$ durante $15 \mathrm{~s}$. O equipamento utilizado neste ensaio foi um microdurômetro da marca Pantec, modelo HXD I000TM.

\subsubsection{Simulação termodinâmica das fases presentes no equilíbrio}

Visando avaliar, de forma isolada, a influência da composição química sobre as temperaturas críticas de transformações de fases, a predição termodinâmica da estabilidade das fases e das frações formadas em função da temperatura no equilíbrio foram realizadas por meio da utilização do software Matcalc, versão base dos dados mc_fe.

\subsubsection{Ensaios de dilatometria}

Os corpos de prova de dilatometria foram usinados a partir do centro dos boletos dos trilhos, na forma de cilindros maciços com $3 \mathrm{~mm}$ de diâmetro e $10 \mathrm{~mm}$ de comprimento. Os ensaios de dilatometria foram realizados em um dilatômetro de têmpera da marca LINSEIS, modelo R.I.T.A. L78.

Para um melhor entendimento da microestrutura resultante, após os aços serem submetidos às diferentes temperaturas de transformação isotérmica, o tamanho de grão austenítico prévio, foi determinado. Para isso, os corpos de prova de cada aço estudado foram aquecidos a uma taxa de $3^{\circ} \mathrm{C} / \mathrm{s}$ até atingir a temperatura de $900^{\circ} \mathrm{C}$, mantidos por I minuto e, em seguida foram resfriados a uma taxa de $200^{\circ} \mathrm{C} / \mathrm{s}$ até a temperatura ambiente. As amostras foram atacadas com o reativo Teepol (solução de ácido pícrico $(2 \mathrm{~g})$, detergente teepol $(\mathrm{Iml})$, ácido clorídrico $(\mathrm{Iml})$, e água destilada $(100 \mathrm{ml})$ por intervalos de tempo suficientes para que os grãos austeníticos prévios fossem revelados. A microestrutura revelada foi avaliada com o auxílio do Software metalográfico quantitativo LAS 4.6 da Leica, no qual foi possível determinar o tamanho médio dos grãos de austenita prévios. Foram quantificados 5 campos em cada aço, fazendo-se uso do método semiautomático do diâmetro equivalente médio, seguindo as orientações das normas ASTM EI I 2 [18] e ASTM EI 382 [22].

Com o intuito de analisar o comportamento dos três aços quando submetidos a diferentes temperaturas de decomposição isotérmica da austenita, os corpos de prova foram aquecidos a uma taxa constante de $3^{\circ} \mathrm{C} / \mathrm{s}$ até a temperatura de $900^{\circ} \mathrm{C}$ e, na sequência, mantidos nesta temperatura por 60 s para completa austenitização. Em seguida, foram resfriados a uma taxa de $200^{\circ} \mathrm{C} / \mathrm{s}$ até as temperaturas em que ocorreram as transformações, que foram: $650,620,600,580,550,520,500,450$ e $400^{\circ} \mathrm{C}$. Após a completa transformação isotérmica (600s), os corpos de prova foram resfriados a uma taxa de $200^{\circ} \mathrm{C} / \mathrm{s}$ até a temperatura ambiente, como mostra a Figura 3.

Para a caracterização microestrutural, foram selecionados três corpos de prova de cada aço estudado, após os mesmos serem submetidos aos diferentes

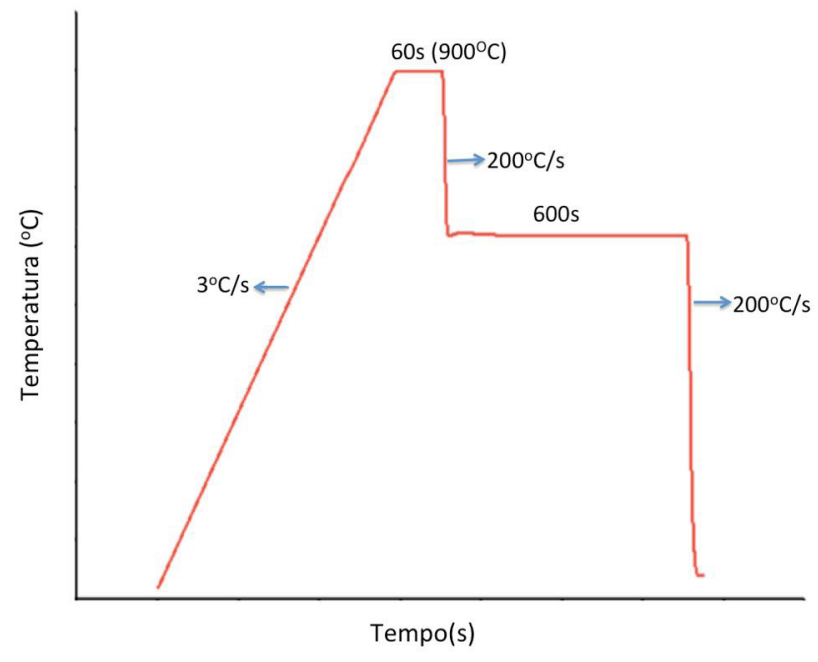

Figura 3. llustração das condições dos ensaios dilatométricos realizados para avaliação da influência da temperatura de transformação isotérmica.

ciclos térmicos (Figura 3). Esses corpos de prova foram estrategicamente selecionados com objetivo de se analisar três diferentes microestruturas: uma microestrutura totalmente perlítica, uma microestrutura mista, constituída por perlita e bainita e finalmente, uma microestrutura majoritariamente bainítica. Os mesmos procedimentos qualitativos e quantitativos aplicados às amostras do estado de entrega, descritos no subitem 2.2.I, foram aplicados aos corpos de prova ensaiados por dilatometria. Também foram feitos os ensaios de microdureza Vickers, com as mesmas condições utilizadas para realização desses ensaios no estado de entrega.

\section{RESULTADOS E DISCUSSÃO}

\section{I Caracterização Microestrutural e Dureza do Estado de Entrega}

$\mathrm{Na}$ Figura 4 são apresentadas micrografias obtidas na região central dos boletos dos trilhos, para os aços $\mathrm{A}, \mathrm{B}$ e $\mathrm{C}$, respectivamente, no estado de entrega. Observa-se que a microestrutura dos três aços, é constituída por perlita fina, sem presença de ferrita pró-eutetóide em contorno de colônias.

A Tabela 2 mostra os resultados do espaçamento interlamelar, tamanho de colônia de perlita e microdureza, no estado de entrega dos três aços analisados. Pela análise microestrutural quantitativa dos aços, é possível observar que as microestruturas dos aços $A$ e $B$ são mais refinadas do que a microestrutura do aço $C$ no estado de entrega.

O valor médio das colônias de perlita apresentado pelo aço $A$ foi menor que os valores apresentados pelos aços B e C. Quanto ao espaçamento interlamelar, os valores apresentados pelos aços $B$ e $C$ são semelhantes, com valor médio ligeiramente menor para o $B$. Já o aço $A$ 

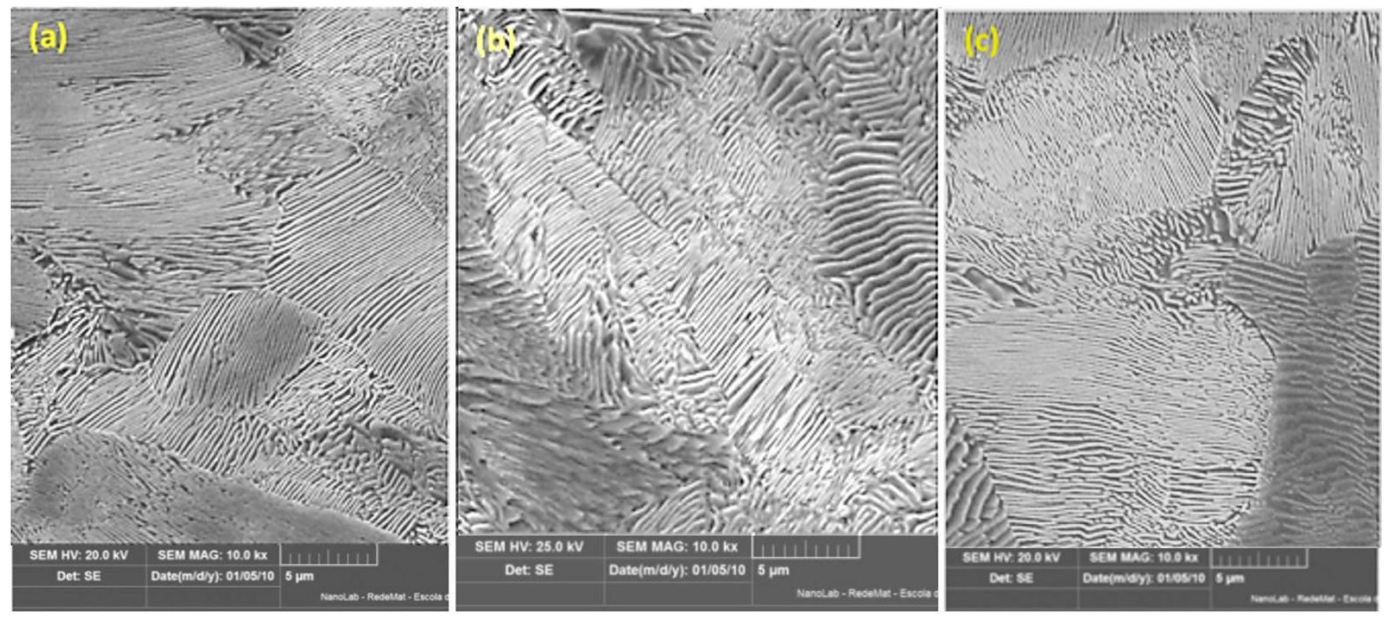

Figura 4. Micrografias dos aços A, B e C, no estado de entrega - ataque Nital 2\%. Aumento de I0000X - MEV.

Tabela 2. Tamanho médio de colônia de perlita, espaçamento interlamelar e Microdureza Vickers dos aços A, B e C no estado de entrega

\begin{tabular}{cccc}
\hline Aço & $\begin{array}{c}\text { Tamanho médio das colônias } \\
\text { de perlita }(\mu \mathrm{m})\end{array}$ & $\begin{array}{c}\text { Espaçamento interlamelar da } \\
\text { perlita }(\mu \mathrm{m})\end{array}$ & Microdureza Vickers \\
\hline A & $28 \pm 2$ & $0,09 \pm 0,01$ & $397 \pm 16$ \\
B & $38 \pm 4$ & $0,15 \pm 0,03$ & $361 \pm 18$ \\
C & $43 \pm 3$ & $0,18 \pm 0,03$ & $325 \pm 15$ \\
\hline
\end{tabular}

apresentou um valor de espaçamento interlamelar perlítico significativamente inferior aos valores apresentados pelos outros dois aços.

A microestrutura mais refinada apresentada pelo aço $A$ e a microestrutura ligeiramente mais refinada apresentada pelo aço $B$ em relação ao aço $C$, deve-se ao tratamento térmico ao final da laminação sofrido pelos aços de classificação premium. Em seus processos atuais de fabricação, os aços $A$ e $B$ são resfriados, após a laminação a quente, sob fluxo de spray de água, o que não acontece para o aço $C$.

Os resultados de dureza apresentam, para os aços $A$ e $B$, valores dentro do especificado para as classes de trilho premium e, para o aço $C$, valores correspondentes à classe standard, segundo a norma AREMA [14] e a International Heavy Haul Association (IHHA). Como consequência da microestrutura mais refinada e aos maiores teores de carbono apresentados pelos aços $\mathrm{A}$ e B, estes obtiveram maiores valores de dureza, comparados ao aço $C$, mesmo este possuindo adição significativa de $\mathrm{Nb}, \mathrm{Ti}$ e $\mathrm{V}$ que, à temperatura ambiente estariam na forma de precipitados finos, e poderiam contribuir com um incremento de dureza. Essa observação, destaca ainda mais, a maior influência dos aspectos morfológicos da perlita sobre o comportamento mecânico nesse tipo de material.

De acordo com alguns trabalhos da literatura [10,23-26], a dureza de um aço perlítico varia de forma inversamente proporcional ao tamanho da colônia de perlita e ao espaçamento interlamelar perlítico. Essas tendências foram igualmente observadas no presente estudo.

\subsection{Simulação Termodinâmica das Fases Presentes no Equilíbrio}

As Figuras 5, 6 e 7 apresentam os resultados obtidos por meio das simulações computacionais realizadas utilizando-se o software Matcalc. Simulou-se as frações das fases presentes nos aços $\mathrm{A}, \mathrm{B}$ e C em função da temperatura, considerando critérios de equilíbrio termodinâmico. $\mathrm{Na}$ Tabela 3 , estão apresentados os valores das temperaturas de início e final de austenitização para os três aços estudados e a temperatura de início de dissolução dos carbonetos (de $\mathrm{Nb}$ e de $\mathrm{Ti}$ ) para $\circ$ aço $C$, obtidos também por meio das simulações termodinâmicas.

De acordo com os resultados, no equilíbrio, os três aços apresentaram temperaturas de início e final de formação da austenita muito próximas. No equilíbrio, a composição química é o único fator a ser considerado, dessa forma, considerando-se que o $\mathrm{C}$ e o Mn são elementos $\gamma$-gêneos (expandem o campo de estabilidade da austenita e abaixam as temperaturas de início e de final de austenitização) e que o Si é um elemento -gêneo (contrai o campo de estabilidade da austenita e aumenta as temperaturas de início e de final de austenitização), as variações desses três elementos, nos três aços seriam os principais fatores que justificariam as temperaturas críticas encontradas serem semelhantes [27]. Por exemplo, o aço $A$ possui maiores teores de carbono e de silício em relação ao aço $B$, porém possui menor teor de manganês. Como o efeito do silício sobre as temperaturas críticas é superior ao do manganês, as temperaturas de 


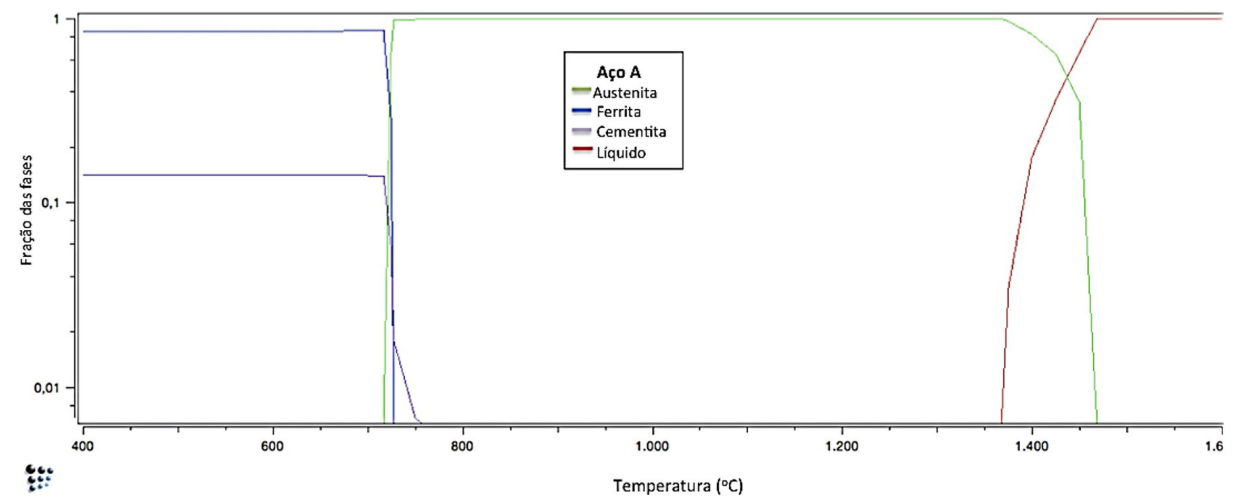

Figura 5. Fração das fases em função da temperatura para o aço $A$ em condições de equilíbrio termodinâmico.

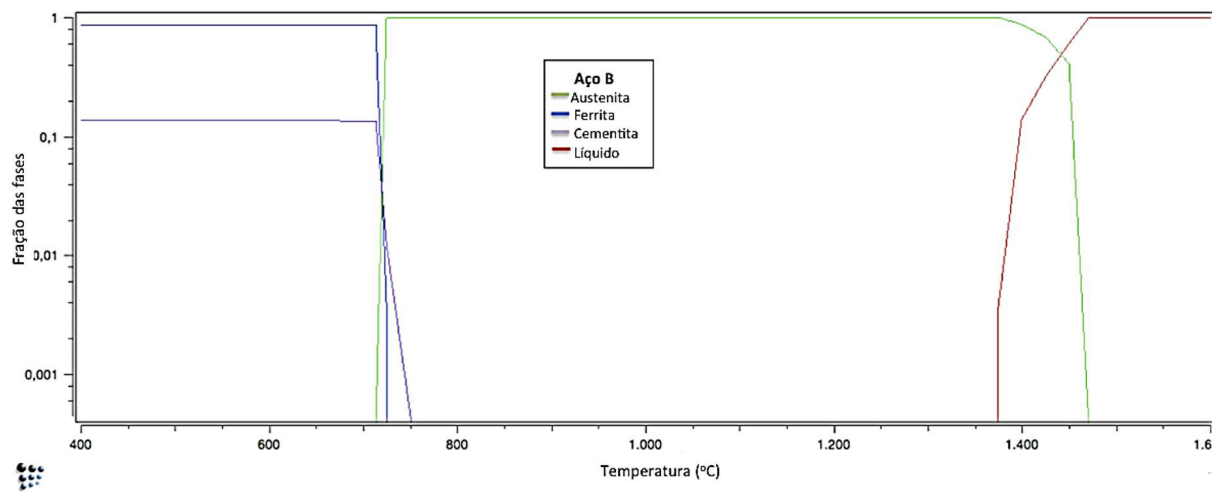

Figura 6. Fração das fases em função da temperatura para o aço B em condições de equilíbrio termodinâmico.

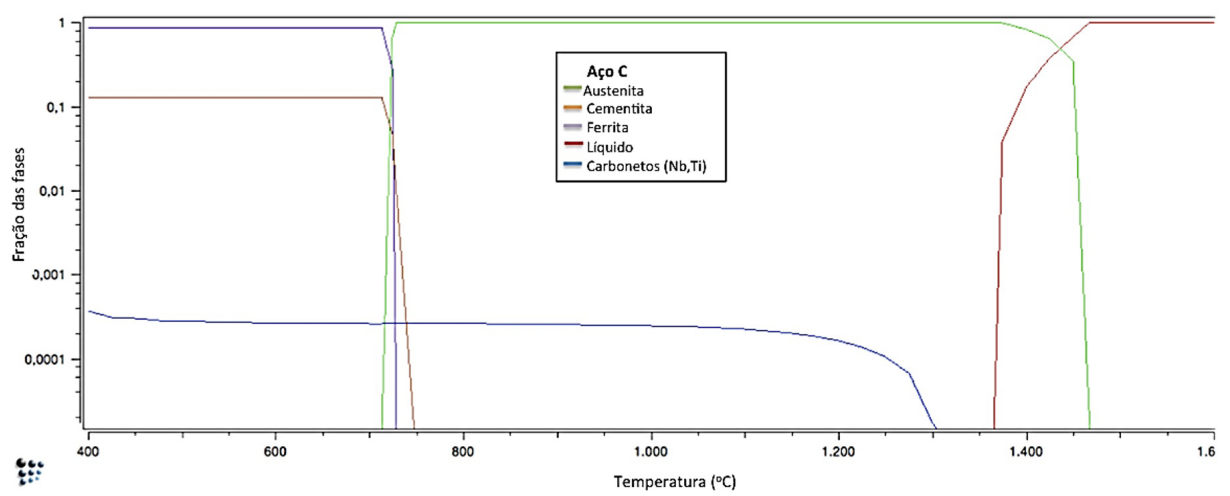

Figura 7. Fração das fases em função da temperatura para o aço $C$ em condições de equilíbrio termodinâmico.

início e final de austenitização do aço A são ligeiramente maiores do que a do aço $B$, no equilíbrio. Ao se comparar os aços B e C, percebe-se que as temperaturas críticas são similares, portanto pode-se afirmar, que o efeito termodinâmico combinado dos elementos químicos $\psi$-gêneos e $\alpha$-gêneos presentes nos aços $\mathrm{A}, \mathrm{B}$ e $\mathrm{C}$ se balanceiam.

Como no equilíbrio, não há uma grande diferença entre as temperaturas críticas apresentadas pelos três aços estudados, pode-se considerar que, fora do equilíbrio, o efeito termodinâmico dos elementos não serão definitivos para justificar diferenças nas temperaturas de transformação, mas sim seus efeitos cinéticos e os efeitos das microestruturas originais.

Além disso, observa-se que a dissolução dos carbonetos de $\mathrm{Nb}$ e $\mathrm{Ti}$, no aço $\mathrm{C}$, aconteceria em temperaturas próximas a $1308^{\circ} \mathrm{C}$, dessa forma, visto que, no presente trabalho, para a realização dos tratamentos isotérmicos, os aços foram aquecidos até a temperatura de $900^{\circ} \mathrm{C}$ (temperatura de austenitização), presume-se não haver alterações significativas na composição química da austenita no aço $\mathrm{C}$ em relação aos teores de $\mathrm{Nb}$ e $\mathrm{Ti}$.

\subsection{Ensaios de Dilatometria}

A Figura 8a apresenta uma curva dilatométrica de austenitização ilustrando o método do desvio mínimo, o qual foi utilizado nesse trabalho para se obter as temperaturas de início e final de austenitização. Este método consiste em considerar as temperaturas críticas $\mathrm{Ac}_{1}$ e $\mathrm{Ac}_{3}$ como 
sendo os pontos a partir dos quais se verifica o início e o fim, respectivamente, do desvio de linearidade na curva de dilatação [28]. Esse procedimento foi executado 9 vezes e a média das temperaturas de início de austenitização dos aços $\mathrm{A}$, B e C, foram, respectivamente, $687^{\circ} \mathrm{C}, 707^{\circ} \mathrm{C}$ e $715^{\circ} \mathrm{C}$, e as temperaturas de final de transformação austenítica, foram, respectivamente, $784^{\circ} \mathrm{C}, 812^{\circ} \mathrm{C}$ e $821^{\circ} \mathrm{C}$, como ilustra a Figura $8 \mathrm{~b}$. Observa-se que, uma vez que a taxa de aquecimento foi constante, o tempo de nucleação da austenita no aço $A$, assim como o tempo necessário para a austenitização completa, é menor do que no aço $B$, e significativamente menor do que no aço $C$. Além disso, deve-se considerar que, para situação correspondente à existência do equilíbrio termodinâmico (Tabela 3), os aços $A$ e $B$ apresentaram temperaturas de início de formação da austenita $\left(A_{1}\right)$ maiores que as temperaturas de início de austenitização apresentadas por esses aços fora do equilíbrio $\left(A c_{1}\right)$, e o aço $C$ apresentou valores de $A$, e $A c$, similares. Dessa forma, sabendo que, de maneira geral a temperatura de início de formação da austenita no equilíbrio termodinâmico é menor do que fora dele e, além disso, nessa condição a composição química é o único fator a ser considerado, pode-se dizer que, a microestrutura inicial influenciou de forma significativa a temperatura de reaustenitização dos três aços estudados.

De acordo com Caballero et al. [29], na reaustenitização da perlita, o fator estrutural mais relevante a ser considerado é o espaçamento interlamelar perlítico. A taxa de crescimento da austenita na perlita aumenta com a diminuição do espaçamento interlamelar. Isso acontece porque a distância efetiva para difusão diminui [30,3I]. Também foi mostrado que, para microestrutura perlítica grosseira, a transformação perlita-austenita inicia-se em temperaturas mais altas [32]. Além disso, alguns autores afirmam que, em aços alto carbono, a adição de $\mathrm{Mn}, \mathrm{Cr}$ e Si dificultam a dissolução da cementita, retardando cineticamente a completa austenitização do aço [33-35]. Neste contexto, pode-se dizer que os resultados obtidos estão coerentes, visto que o aço $A$, além de possuir a estrutura inicial mais refinada que o aço $B$ e $C$, possui os menores teores de $\mathrm{Mn}$ e $\mathrm{Cr}$ em sua composição.

No estudo da decomposição isotérmica da austenita, para definir os intervalos de tempo de início e final de transformação, foi utilizado o método das derivadas. Como está ilustrado na Figura 9a, o tempo de início e final de decomposição da austenita em constituintes eutetóides é definido como o intervalo de tempo, em relação ao início do resfriamento, entre os pontos nos quais a curva da derivada passa pelo valor zero, ou seja, a tangente da curva de dilatação fica horizontal em relação ao eixo do tempo (pontos indicados pelas setas vermelhas) [36]. Depois de obtidos os tempos de início e final de decomposição da austenita para cada temperatura de transformação $\left(650,620,600,580,550,520,500,450\right.$ e $\left.400^{\circ} \mathrm{C}\right)$, foi possível determinar o diagrama TTT para cada aço estudado. A Figura $9 b$ apresenta um comparativo entre os diagramas obtidos para os três aços.

Pode-se observar que a curva do aço A $(0,790 \%$ de $\mathrm{C}$ e $0,880 \%$ de $\mathrm{Mn}$ ) está deslocada para esquerda
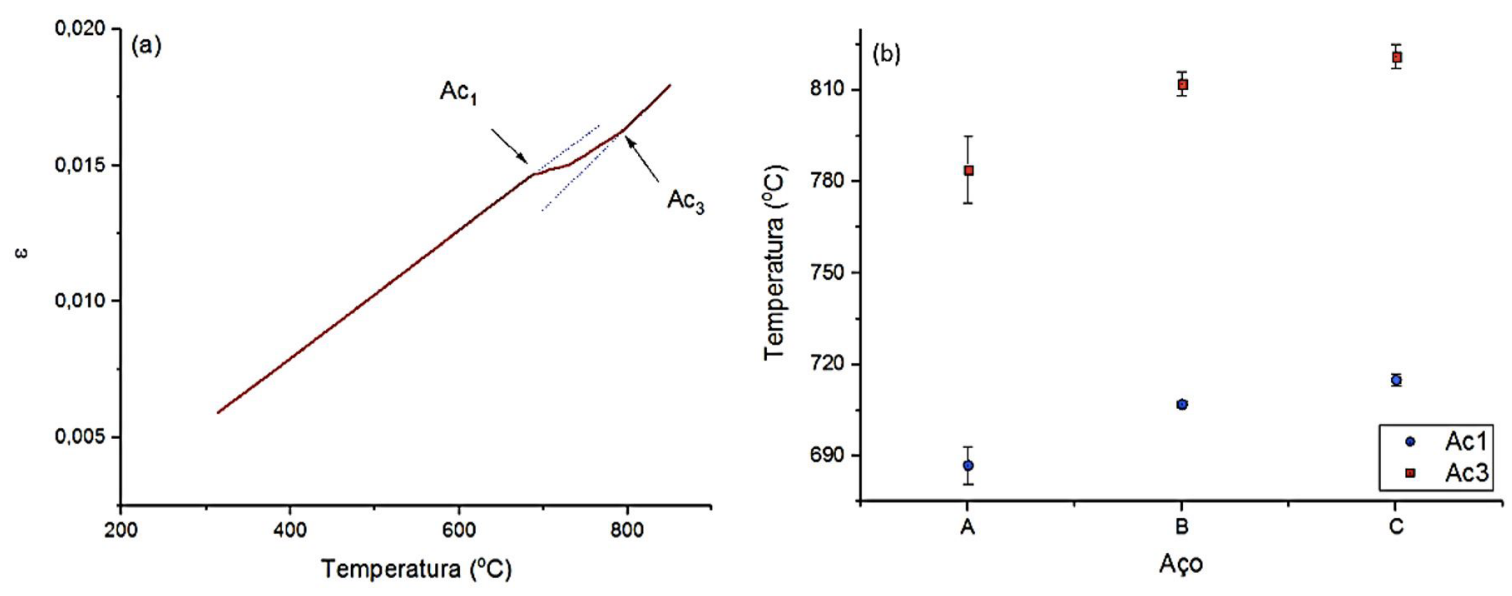

Figura 8. (a) Curva de austenitização ilustrando o método do desvio mínimo para obter as temperaturas de início $\left(A c_{1}\right)$ e final de austenitização $\left(A c_{3}\right)$; (b) Temperaturas críticas de austenitização com os valores médios e desvios médios correspondentes aos aços A, B e C.

Tabela 3. Temperaturas de início e final de formação da austenita e temperatura de dissolução de carbonetos obtidas por meio das simulações computacionais realizadas utilizando-se o software Matcalc

\begin{tabular}{cccc}
\hline Aço & $\begin{array}{c}\text { Temperatura de início de } \\
\text { formação da austenita no } \\
\text { equilíbrio }\left({ }^{\circ} \mathbf{C}\right)\end{array}$ & $\begin{array}{c}\text { Temperatura de final de } \\
\text { formação da austenita no } \\
\text { equilíbrio }\left({ }^{\circ} \mathbf{C}\right)\end{array}$ & $\begin{array}{c}\text { Temperatura de dissolução } \\
\text { dos carbonetos }(\mathbf{N b} \text { e Ti) no } \\
\text { equilíbrio }\left({ }^{\circ} \mathbf{C}\right)\end{array}$ \\
\hline A & 717 & 729 & - \\
B & 713 & 724 & - \\
C & 713 & 729 & 1308 \\
\hline
\end{tabular}


em relação ao aço $B(0,760 \%$ de $C$ e $I, 017 \%$ de $M n)$ e, significativamente mais deslocada para esquerda em relação ao aço $C(0,730 \%$ de $C$ e I, $240 \%$ de $\mathrm{Mn})$. A maior concentração de carbono propicia a maior estabilidade da austenita, deslocando a curva TTT para direita. Porém, nesse caso, visto que $\circ$ aço $A$ apresentou o maior teor desse elemento e mesmo assim sua curva está deslocada para esquerda em relação aos outros dois aços, pode-se dizer que o teor de carbono não exerceu uma influencia significativa no deslocamento das curvas de transformação de fases isotérmicas dos aços $A, B$ e C. Esta observação pode ser explicada principalmente em função da diferença dos teores de $\mathrm{Mn}$ nos aços estudados. A maior concentração de $M n$ no aço $C$ diminui a concentração de carbono da transformação eutetóide e propicia maior estabilidade da austenita mesmo em temperaturas abaixo de $\mathrm{Ac}_{1}$. Assim sendo, a cinética de decomposição da austenita, no aço $C$, é retardada, justificando a sua curva mais deslocada para a direita em relação aos aços A e B [37-39].

\subsection{Caracterização Microestrutural e Microdureza dos Corpos de Prova de Dilatometria}

A Figura 10 apresenta as microestruturas dos corpos de prova de dilatometria submetidos à temperatura de transformação isotérmica de $650^{\circ} \mathrm{C}$. Observa-se que, os corpos de prova selecionados para caracterização microestrutural e microdureza Vickers, apresentam uma microestrutura completamente perlítica.

Os resultados do tamanho médio de colônia de perlita, espaçamento interlamelar e microdureza Vickers, apresentados pelos aços $\mathrm{A}, \mathrm{B} \mathrm{e} \mathrm{C}$, submetidos à temperatura de transformação isotérmica de $650^{\circ} \mathrm{C}$, são apresentados na Tabela 4. (a)

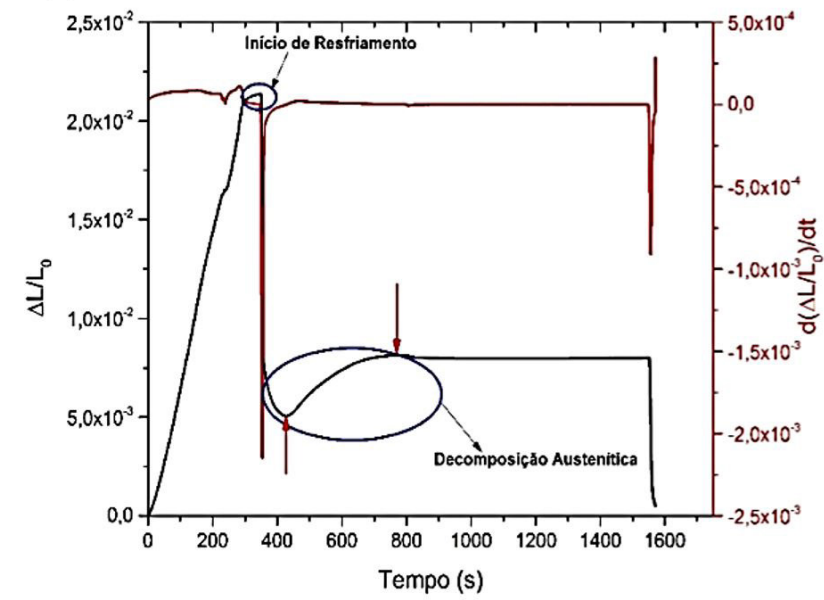

(b)

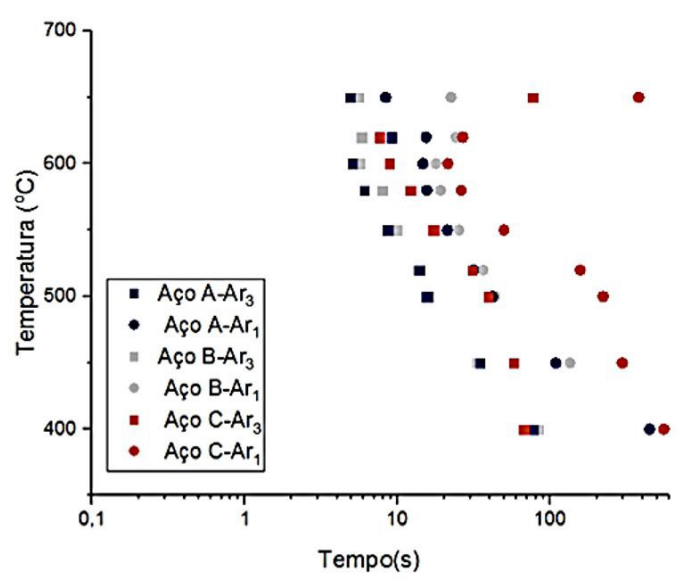

Figura 9. (a) Ilustração do método das derivadas em uma curva Variação de Comprimento Relativo em relação ao Tempo. (b) Comparativo dos diagramas TTT dos aços A, B e C determinados a partir dos aços austenitizados a $900^{\circ} \mathrm{C}$.
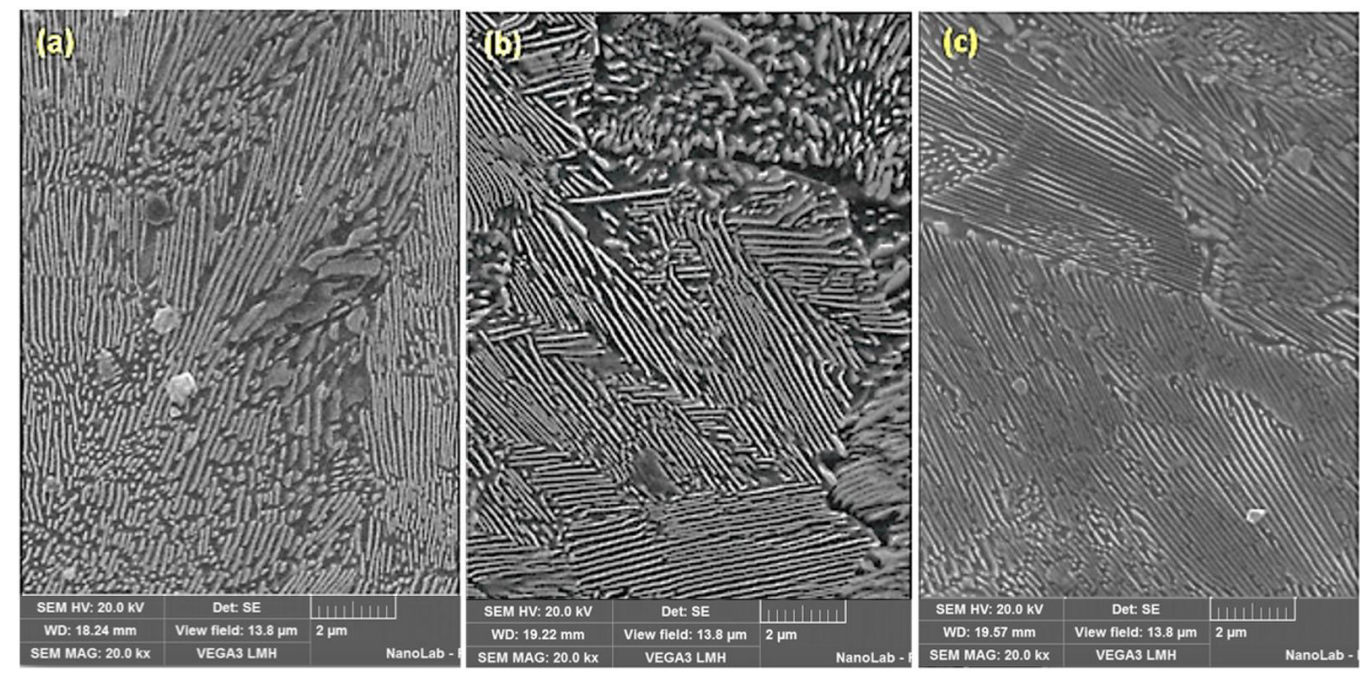

Figura 10. Micrografias dos aços a, b e c, após serem submetidos à transformação isotérmica a $650^{\circ} \mathrm{C}$. Ataque Nital $2 \%$, aumento de $20000 \mathrm{X}$ - MEV. 
Tabela 4. Tamanho médio de colônia de perlita, espaçamento interlamelar, tamanho de grão austenítico prévio e microdureza Vickers dos aços $\mathrm{A}, \mathrm{B}$ e C submetidos a temperatura de transformação isotérmica de $650^{\circ} \mathrm{C}$

\begin{tabular}{ccccc}
\hline Aço & $\begin{array}{c}\text { Tamanho médio das } \\
\text { colônias de perlita }(\mu \mathrm{m})\end{array}$ & $\begin{array}{c}\text { Espaçamento } \\
\text { interlamelar da perlita } \\
(\boldsymbol{\mu m})\end{array}$ & $\begin{array}{c}\text { Tamanho de grão } \\
\text { austenítico prévio }(\boldsymbol{\mu m})\end{array}$ & $\begin{array}{c}\text { Microdureza Vickers } \\
(\mathbf{H V})\end{array}$ \\
\hline A & $22 \pm 2$ & $0,11 \pm 0,01$ & $25 \pm 11$ & $352 \pm 11$ \\
B & $25 \pm 3$ & $0,13 \pm 0,01$ & $34 \pm 15$ & $323 \pm 7$ \\
C & $12 \pm 1$ & $0,12 \pm 0,02$ & $13 \pm 6$ & $333 \pm 6$ \\
\hline
\end{tabular}

Como era esperado, observou-se que, a diferença do tamanho de grão austenítico prévio entre os aços premium e standard foi bastante significativa. De acordo com estudos encontrados na literatura, a taxa de formação da austenita no aquecimento é controlada pela taxa de crescimento dos grãos austeníticos, e o crescimento dos grãos austeníticos é controlado principalmente pela taxa de difusão de carbono na austenita entre lamelas de cementita e ferrita adjacentes $[30,31,40]$. A difusão dos átomos de carbono ocorre a distâncias médias da ordem do espaçamento interlamelar da perlita e, sendo assim, a taxa de crescimento da austenita na perlita aumenta com a diminuição do espaçamento interlamelar, ou seja, uma microestrura perlítica mais refinada, propicia grãos austeníticos maiores durante a etapa de austenitização, como foi o caso dos aços premium. Os maiores teores de $\mathrm{Nb}$ e Ti presentes na composição química do aço $C$, também podem ter contribuído para o refino do grão austenítico prévio nesse aço, haja visto que os carbonetos formados a partir desses elementos não foram dissolvidos durante a austenitização a $900^{\circ} \mathrm{C}$, atuando assim como mecanismo de ancoramento de contornos de grão austenítico. Além disso, o efeito de arraste de soluto do $\mathrm{Mn}$ e do $\mathrm{Si}$, elementos encontrados em maior quantidade no aço C, pode ter colaborado, de certa forma, para restringir o crescimento de grão austenítico no aço C [4I].

Em relação ao tamanho de colônias de perlita, a diferença entre os aços premium e standard também foi significativa. O menor tamanho de colônia de perlita apresentado no estado de entrega pelos aços premium em relação ao standard pode estar relacionado ao grau de super-resfriamento a que os aços premium foram submetidos. No entanto, após os três aços serem submetidos à mesma temperatura de transformação isotérmica, o aço $\mathrm{C}$ apresentou uma diferença significativa em relação aos aços $A$ e $B$, e em relação ao seu estado de entrega. O tamanho da colônia de perlita é controlado pelo tamanho de grão inicial da austenita, ou seja, quanto menor o tamanho de grão austenítico prévio, menor será o tamanho das colônias de perlita $[8,9,42,43]$. Dessa forma, pode-se dizer que os resultados estão coerentes, visto que, os aços $A$ e $B$ apresentaram um maior tamanho de grão austenítico prévio e, consequentemente um maior tamanho de colônia de perlita em relação ao aço C.

Após o tratamento isotérmico proposto nesse estudo, os valores do espaçamento interlamelar perlítico médio, apresentado pelos aços premium, mostram que, não existe uma diferença significativa quando esses valores são comparados aos valores do espaçamento interlamelar perlítico médio apresentando por esses aços no estado de entrega. Porém, é importante observar que o aço $C$, apresentou uma grande diferença entre os valores do espaçamento interlamelar do estado de entrega e após ser submetido a etapa de tratamento térmico. Este fato pode estar relacionado aos maiores teores de $\mathrm{Mn}$ e Si contidos na composição química do aço $C$ juntamente ao efeito do grau de super-resfriamento durante a decomposição da austenita.

Com aumento dos teores de $\mathrm{Mn}$ e $\mathrm{Si}$, a difusão do carbono é dificultada e, a austenita se torna mais estável mesmo em temperaturas abaixo de $A c_{1}$, retardando a formação de novos núcleos de perlita. Como esses elementos diminuem a concentração de carbono da reação eutetóide, os primeiros núcleos de perlita formados teriam origem com uma concentração mais baixa de carbono e a austenita remanescente ficaria enriquecida em carbono [44]. Dessa forma, como a concentração de carbono na austenita remanescente é mais elevada, a distância média de difusão desse elemento na austenita vai diminuindo, justificando a diminuição do espaçamento interlamelar com a evolução da transformação.

O maior valor de dureza apresentado pelo aço $A$ provavelmente se deve ao fato desse aço ter apresentado o maior teor de carbono e o menor valor de espaçamento interlamelar, apesar de não ter apresentado o menor valor de tamanho de colônia de perlita e nem o menor valor de tamanho de grão austenítico. Hyzak e Bernstein [9] quantificaram o efeito do tamanho de grão austenítico, do espaçamento interlamelar da perlita e do tamanho das colônias de perlita nas propriedades mecânicas de aços eutetóides. Os autores concluíram que o espaçamento interlamelar perlítico é o mais importante parâmetro microestrutural que controla a resistência mecânica de aços perlíticos.

Além disso, deve-se destacar que o aumento significativo da dureza do aço $C$ em relação ao aço $B$, se deve ao maior refinamento da microestrutura do aço $C$, em consequência do tratamento térmico sofrido pelo mesmo.

Este resultado se mostra relevante, pois há um indicativo favorável que, uma vez que se caracteriza a cinética de transformação de fases de aços eutetóides de aplicação ferroviária e se mapeie os diagramas TTT desses aços, utilizando-os como referência para que planejamentos adequados de tratamentos térmicos sejam executados, há potencial para se obter características microestruturais para 
aços standard tão refinadas quanto as alcançadas para aços premium como fabricados.

As Figuras II e 12 apresentam as microestruturas dos corpos de dilatometria submetidos às temperaturas de transformação isotérmica de $550^{\circ} \mathrm{C} \mathrm{e} 400^{\circ} \mathrm{C}$.

A bainita é um produto de transformação que fica abaixo do "nariz" da curva de transformação, mas acima da temperatura inicial de transformação martensítica. Se o diagrama de transformação isotérmica (TTT) não exibe um campo distinto de bainita, a formação desse microconstituinte será acompanhada pela formação de perlita a temperaturas logo abaixo do nariz da curva de transformação perlítica. Em temperaturas mais baixas, mas acima do início da transformação martensítica, a bainita será o produto majoritário [45].

Dessa forma, pode-se observar que, na temperatura de $550^{\circ} \mathrm{C}$, os três aços estudados, apresentaram uma microestrutura mista, constituída de bainita e perlita. Os corpos de provas submetidos a temperatura de transformação isotérmica de $400^{\circ} \mathrm{C}$, apresentaram uma microestrutura majoritariamente bainítica, em acordo com - que é descrito na literatura para morfologias de bainita em aços alto carbono [45]. Os resultados mostram que, é possível obter uma microestrutura bainítica a partir de aços eutetóides, de classificação tanto premium quanto standard, por meio de um tratamento térmico bem planejado.
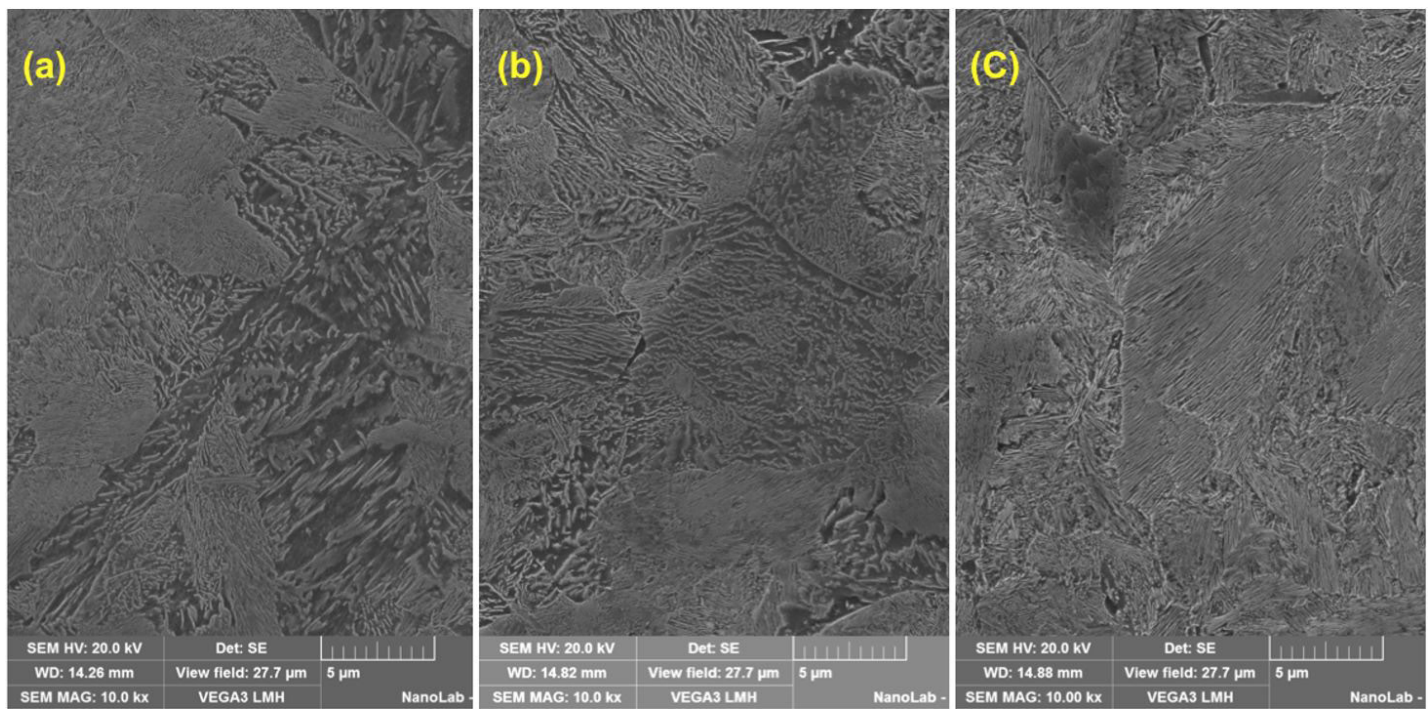

Figura II. Micrografias dos aços a, b e c, após serem submetidos à transformação isotérmica a $550^{\circ} \mathrm{C}$. Ataque Nital $2 \%$, aumento de I0000X - MEV.

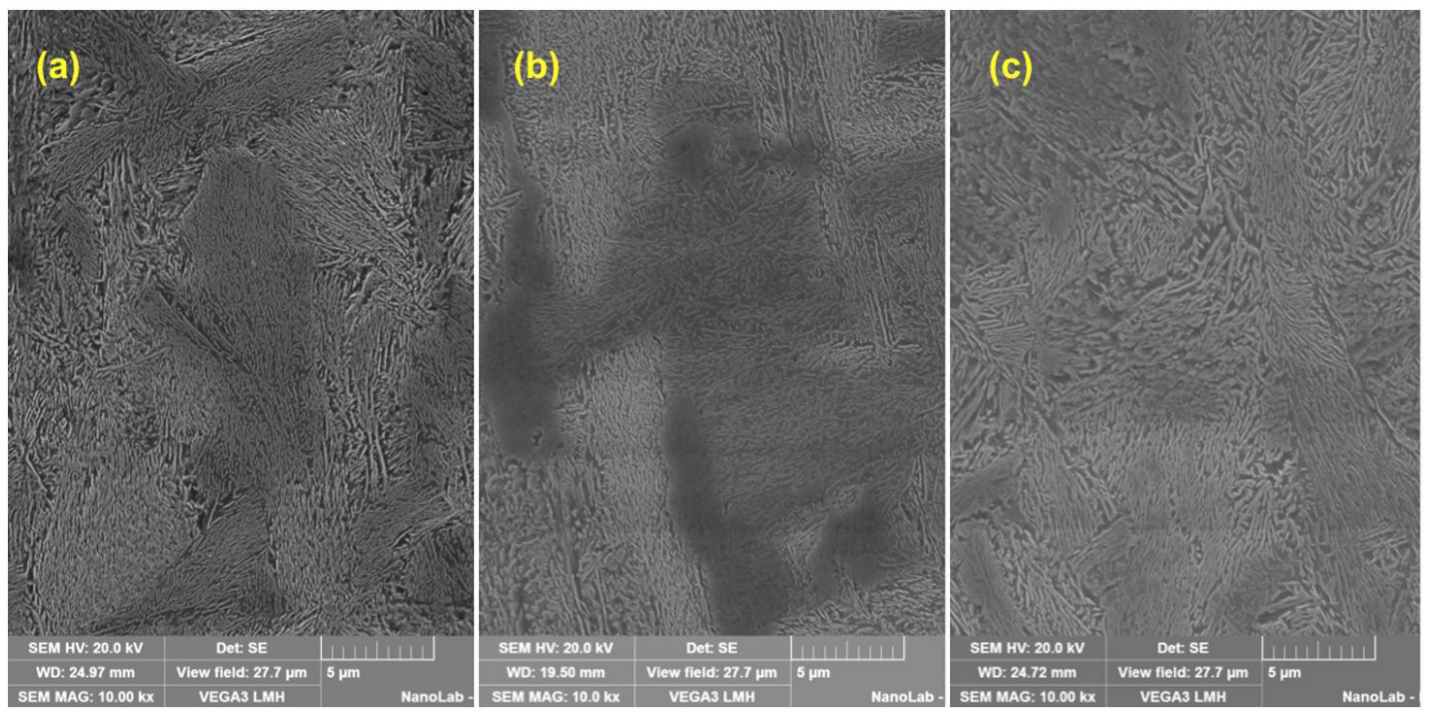

Figura 12. Micrografias dos aços a, b e c, após serem submetidos à transformação isotérmica a $400^{\circ} \mathrm{C}$. Ataque Nital $2 \%$, aumento de $10000 \mathrm{X}$ - MEV. 
Tabela 5. Microdureza Vickers apresentada pelos aços A, B e C, submetidos as temperaturas de transformação isotérmicas de $550^{\circ} \mathrm{C}$ e $400^{\circ} \mathrm{C}$

\begin{tabular}{ccc}
\hline \multirow{2}{*}{ Aço } & \multicolumn{2}{c}{ Microdureza Vickers (HV) } \\
\cline { 2 - 3 } & $\mathbf{5 5 0 ^ { \circ } \mathbf { C }}$ & $\mathbf{4 0 0 ^ { \circ } \mathbf { C }}$ \\
\hline A & $452 \pm 11$ & $456 \pm 9$ \\
B & $413 \pm 11$ & $454 \pm 5$ \\
C & $424 \pm 16$ & $441 \pm 8$ \\
\hline
\end{tabular}

Os valores de microdureza Vickers apresentados pelos aços $A, B$ e $C$, submetidos às temperaturas de transformação isotérmica de $550^{\circ} \mathrm{Ce} 400^{\circ} \mathrm{C}$, são apresentados na Tabela 5.

Diante desses valores, é possível observar que, os corpos de prova que apresentaram uma microestrutura majoritariamente bainítica, apresentaram maior dureza em relação aos corpos de prova que apresentaram uma microestrutura majoritariamente perlítica e os corpos de prova que apresentaram uma microestrutura mista, constituída de perlita e bainita.

\section{CONCLUSÕES}

O tempo de nucleação da austenita no aço $A$, é menor do que no aço $B$, e significativamente menor do que no aço $C$. O menor espaçamento interlamelar perlítico apresentado pelo aço $A$ no estado de entrega e, os menores teores de $\mathrm{Mn}$ e $\mathrm{Cr}$ contidos na composição química desse aço, são as principais causas desse comportamento.

Durante a transformação isotérmica, o tempo de nucleação da perlita no aço $A$ é menor do que no aço $B$ e significativamente menor do que no aço $C$. A menor concentração de $\mathrm{Mn}$ no aço $\mathrm{A}$ seria a principal causa deste comportamento.
Após os três aços serem submetidos ao tratamento isotérmico a $650^{\circ} \mathrm{C}$, o aço classificado como standard, apresentou um maior endurecimento em relação aos aços classificados como premium. O principal motivo do aumento da dureza apresentado pelo aço standard, seria a diminuição significativa do espaçamento interlamelar perlítico apresentado por esse aço, após o mesmo ser submetido ao processamento térmico proposto nesse estudo.

A microestrutura mais grosseira apresentada pelo aço standard no estado de entrega, em conjunto com o efeito do maior teor de elementos de liga como $\mathrm{Nb}$ e $\mathrm{Ti}$, e com o efeito de arraste de soluto do $\mathrm{Mn}$ e do $\mathrm{Si}$, elementos encontrados em maior quantidade no aço $\mathrm{C}$, contribuíram para que esse aço apresentasse um menor tamanho de grão austenítico prévio em relação aos aços premium e, consequentemente menor tamanho de colônias de perlita após a transformação isotérmica.

Os aços de classificação premium e o aço de classificação standard, submetidos a temperatura de transformação isotérmica de $550^{\circ} \mathrm{C}$, apresentaram uma microestrutura mista, constituída de bainita e perlita. Os mesmos submetidos a temperatura de transformação isotérmica de $400^{\circ} \mathrm{C}$, apresentaram uma microestrutura majoritariamente bainítica. Os aços que obtiveram uma microestrutura majoritariamente bainítica, apresentaram um maior valor de microdureza em relação aos aços que apresentaram uma microestrutura mista, constituída de bainita e perlita.

\section{Agradecimentos}

À Universidade Federal de Ouro Preto e ao Conselho Nacional de Desenvolvimento Científico e Tecnológico (CNPq), pelas bolsas auxílio de Mestrado e Iniciação Científica e pela bolsa de produtividade em pesquisa.

\section{REFERÊNCIAS}

I Sahay SS, Mohapatra GT. Overview of pearlitic rail steel: accelerated cooling, quenching, microstructure, and mechanical properties. Journal of ASTM International. 2009;6(7): I-25.

2 Porcaro RR, Faria GL, Godefroid LB, Apolonio GR, Candido LC, Pinto ES. Microstructure and mechanical properties of a flash buttwelded pearlitic rail. Materials Processing Technology. 2019;270:20-27. http://dx.doi. org/10.1016/j.jmatprotec.2019.02.013.

3 Nishikawa LP, Goldenstein H. Divorced eutectoid on heat-affected zone of welded pearlitic rails. The Journal of The Minerals, Metals \& Materials Society (TMS). 20I9;7I(2):8I5-823. https://doi.org/I0. I007/s I 1837-0I8-32I3-5.

4 Taleff EM, Lewandowski J], Pourladian B. Microstructure-property relationships in pearlitic eutectoid and hypereutectoid carbon steels. Journal of The Minerals, Metals \& Materials Society (TMS). 2002;54(7):25-30. http:// dx.doi.org/10.1007/BF02700982.

5 Offerman SE, van Wilderen LJGW, van Dijk NH, Sietsma J, Rekveldt MT, van der Zwaag S. In-situ study of pearlite nucleation and growth during isothermal austenite decomposition in nearly eutectoid steel. Acta Materialia. 2003;5I(I3):3927-3938. http://dx.doi.org/I0.1016/S1359-6454(03)002 I7-9.

6 Pickering FB. Physical metallurgy and the design of steels. USA: Applied Sciences Publishers; 1978. p. 90- 100. 
7 Wang M, Zhang F, Yang Z. Effects of high-temperature deformation and cooling process on the microstructure and mechanical properties of an ultrahigh-strength pearlite steel. Materials \& Design. 2017;1 I4:102-1 I0. http://dx.doi. org/l0.1016/j.matdes.2016.10.049.

8 Marder AR, Bramfitt BL. The effect of morphology on the strength of pearlite. Metallurgical Transactions. A, Physical Metallurgy and Materials Science. 1976;7(3):365-372. http://dx.doi.org/I0.1007/BF02642832.

9 Hyzak JM, Bernstein IM. The role of microstructure on the strength and toughness of fully pearlitic steels. Metallurgical Transactions. A, Physical Metallurgy and Materials Science. 1976;7(8):I217- I224. http://dx.doi. org/I0.1007/BF02656606.

10 Dollar M, Bernstein IM, Thompson AW. Influence of deformation substructure on flow and fracture of fully pearlitic steel. Acta Metallurgica. 1988;36(2):3II-320. http://dx.doi.org/I0.1016/000I-6160(88)90008-9.

I I Godefroid LB, Moreira LP, Vilela TCG, Faria GL, Candido LC, Pinto ES. Effect of chemical composition and microstructure on the fatigue crack growth resistance of pearlitic steels for railroad application. International Journal of Fatigue. 2019;120:24I-253. http://dx.doi.org/10.1016/j.jfatigue.2018.10.016.

12 Farhangi H, Mousavizadeh SM. Horizontal split-web fractures of flash butt welded rails. In: Proceedings of the 8th International Fracture Conference; 2007; Istanbul, Turkish. Istanbul. p. 509-5I7.

13 Tawfik D, Mutton PJ, Chiu WK. Transient thermal stress analysis on rapid post-weld heat treatments applied to flash butt welded rails. Science and Technology of Welding and Joining. 2006; I I (3):326-336. http://dx.doi. org/10.1 179/174329306X107629.

14 American Railway Engineering and Maintenance-of-Way Association. Manual for railway engineering. Lanham, Maryland: AREMA; 2013.

15 Lee KM, Polycarpou AA. Wear of conventional pearlitic and improved bainitic rail steels. Wear. 2005;259(I-6):39I399. http://dx.doi.org/10.1016/j.wear.2005.02.058.

16 Aglan HA, Liu ZY, Hassan MF, Fateh M. Mechanical and fracture behavior of bainitic rail steel. Journal of Materials Processing Technology. 2004; I5I(I-3):268-274. http://dx.doi.org/I0.10I6/j.jmatprotec.2004.04.073.

17 American Society for Testing and Materials. ASTM E3: Standard Guide for Preparation of Metallographic Specimens. West Conshohocken: ASTM; 2017.

I8 American Society for Testing and Materials. ASTM EI I 2: Standard Test Methods for Determining Average Grain Size. West Conshohocken: ASTM; 2014.

19 Silva PRT. Caracterização de trilhos ferroviários quanto a tenacidade à fratura e comportamento em fadiga. [dissertação]. Porto Alegre: Universidade Federal do Rio Grande do Sul; 1995.

20 Gomes MGMF, Almeida LH, Gomes LCFC, May IL. Effects of microstructural parameters on the mechanical properties of eutectoid rail steels. Materials Characterization. 1997;39(I):I-14. http://dx.doi.org/I0.1016/SI0445803(97)00086-7.

2I Limberger IF. Estudo da propagação de trincas transversais por fadiga em trilhos ferroviários [tese]. Porto Alegre: Universidade Federal do Rio Grande do Sul; 2000.

22 American Society for Testing and Materials. ASTM E 1382: Standard Test Methods for Determining Average Grain Size Using Semiautomatic and Automatic Image Analysis. West Conshohocken: ASTM; 2015.

23 Clayton P, Devanathan R. Rolling/sliding wear behavior of a chromium- molybdenum rail steel in pearlitic and bainitic conditions. Wear. 1992;156(I):121-131. http://dx.doi.org/10.1016/0043-1648(92)90148-2.

24 Olivares RO, Garcia Cl, Deardo A, Kalay S, Hernández FCR. Advanced metallurgical alloy design and thermomechanical processing for rails steels for North American heavy haul use. Wear. 20I I;27I(I-2):364-373. http://dx.doi.org/I0.1016/j.wear.2010.10.048.

25 Gladman T, Mclvor ID, Pickering FB. Some aspects of the structure - property relationship in high-carbon ferritepearlite steels. ISIJ International. 1972:916-930.

26 Moreira LP. Efeito de características microestruturais na tenacidade à fratura e no crescimento de trinca por fadiga de aços perlíticos de aplicação ferroviária [dissertação] Ouro Preto: Rede Temática em Engenharia de Materiais, Universidade Federal de Ouro Preto; 2015.

27 Krauss G. Processing, structure, and performance. Ohaio: ASM International; 2005.

28 Andrés CG, Caballero FG, Capdevila C, Álvarez LF. Application of dilatometric analysis to the study of solid-solid phase transformations in steels. Materials Characterization. 2002;48(I):I0I-III. http://dx.doi.org/I0.1016/SI0445803(02)00259-0. 
29 Caballero FG, Capdevila C, Andrés CG. Influence of scale parameters of pearlite on the kinetics of anisothermal pearlite-to-austenite transformation in a eutectoid steel. Scripta Materialia. 2000;42(I2): I I59-I I65. http://dx.doi. org/I0.1016/SI359-6462(00)00352-3.

30 Roosz A, Gacsi Z, Fuchs EG. Isothermal formation of austenite in eutectoid plain carbon steel. Acta Metallurgica. |983;3 | (4):509-5 I7. http://dx.doi.org/I0.1016/000 I-6160(83)90039-I.

3I Jacot A, Rappaz M, Reed RC. Modelling of reaustenitization from the perlite structure in steel. Acta Metallurgica. 1998;46(II):3949-3962.

32 Caballero FG, Capdevila C, Andrés CG. Modelling of isothermal formation of pearlite and subsequent reaustenitisation in eutectoid stell during continuous heating. Materials Science and Technology. 200 I; 17(6):686-692. http://dx.doi.org/I0.1 I 79/02670830I I0I5I 040 I.

33 Zhang G, Chae J, Kim K, Suh DW. Effects of Mn, Si and Cr addition on the dissolution and coarsening of pearlitic cementite during intercritical austenitization in fe-I mass\% alloy. Materials Characterization. 20I3;8I:56-67. http:// dx.doi.org/10.1016/j.matchar.2013.04.007.

34 Miyamoto G, Usuki H, Li Z-D, Furuhara T. Effects of Mn, Si and Cr addition on reverse transformation at I073K from spheroidized cementite structure in Fe-0.6 mass\% C alloy. Acta Materialia. 20 I0;58(I3):4492-4502. http:// dx.doi.org/10.1016/j.actamat.2010.04.045.

35 Karmazin L, Krejci J. The dependence of the austenitization kinetics on the type of initial spheroidized structure in low alloy steel. Materials Science and Engineering. 1994; I85(I-2):5-7. http://dx.doi.org/10.1016/092 I5093(94)90944-X.

36 Pawlowski B, Bala P, Dziurka R. Improper interpretation of dilatometric data for cooling transformations in steels. Arquives of Metallurgy and Materials. 20 I4:I I59-I I 6I. http://dx.doi.org/I0.2478/amm-2014-0202.

37 Wang L, Wang Z, Lu K. Grain size effects on the austenitization process in a nanostructured ferritic steel. Acta Materialia. 2011;59(9):3710-3719. http://dx.doi.org/10.1016/j.actamat.2011.03.006.

38 Zhao JC, Notis MR. Continuous cooling transformation kinetics versus isothermal transformation kinetics of steels: a phenomenological rationalization of experimental observations. Materials Science and Engineering. 1995; 15(45):135-207. http://dx.doi.org/10.1016/0927-796X(95)00183-2.

39 Prakash AK, Brimacombe JK. Mathematical model of heat flow and austenite-perlite transformation in eutectoid carbon steel rods for wire. Metallurgical Transactions. B, Process Metallurgy. 1981;12(I): I2I-I 33.

40 Brooks CR. Principles of the austenitization of steels. London: Elsevier Science; 1992.

4I Seol JB, Raabe D, Choi PP, Im YR, Park CG. Atomic scale effects of alloying, partitioning, solute drag and austempering on the mechanical properties of high-carbon bainitic-austenitic TRIP steels. Acta Materialia. 2012;60(17):6183-6199. http://dx.doi.org/10.1016/j.actamat.2012.07.064.

42 Vicente FA, Carsí M, Penãlba F, Taleff E, Ruano OA. Toughness dependence on the microstructural parameters for an ultrahigh carbon steel (I.3 wt.\% C). Materials Science and Engineering. 200 I;335(I-2): I75-I 85.

43 Lewandowski JJ, Thompson AW. Effects of the prior austenite grain size on the ductility of fully pearlitic eutectoid steel. Metallurgical Transactions. A, Physical Metallurgy and Materials Science. 1986; 17(3):46I-472. http://dx.doi. org/I0.1007/BF02643953.

44 Puls MP, Kirkaldy JS. The pearlite reaction. Metallurgical Transactions. 1972;3(I I):2777-2796. http://dx.doi. org/10.1007/BF02652844.

45 Steele RK. Steel alloys with lower bainite microstructures for use in railroad cars and track. USA: U.S. Department of Transportation; 2002.

Recebido em: 21 Jan. 2018

Aceito em: 10 Jul. 2019 